\title{
Disk displacement, eccentric condylar position, osteoarthrosis - misnomers for variations of normality? Results and interpretations from an MRI study in two age cohorts
}

Jens C. Türp ${ }^{1 *}$, Anna Schlenker ${ }^{2}$, Johannes Schröder ${ }^{3}$, Marco Essig $^{4}$ and Marc Schmitter ${ }^{5}$

\begin{abstract}
Background: Clinical decision-making and prognostic statements in individuals with manifest or suspected temporomandibular disorders (TMDs) may involve assessment of (a) the position of articular disc relative to the mandibular condyle, (b) the location of the condyle relative to the temporal joint surfaces, and (c) the depth of the glenoid fossa of the temporomandibular joints (TMJs). The aim of this study was twofold: (1) Determination of the prevalence of these variables in two representative population-based birth cohorts. (2) Reinterpretation of the clinical significance of the findings.

Methods: From existing magnetic resonance imaging (MRI) scans of the TMJs that had been taken in 2005 and 2006 from 72 subjects born between 1930 and 1932 and between 1950 and 1952, respectively, the condylar position at closed jaw was calculated as percentage displacement of the condyle from absolute centricity. By using the criteria introduced by Orsini et al. (Oral Surg Oral Med Oral Pathol Oral Radiol Endod 86:489-97, 1998), a textbook-like disc position at closed jaw was distinguished from an anterior location. TMJ morphology of the temporal joint surfaces was assessed at open jaw by measuring the depth of the glenoid fossa, using the method proposed by Muto et al. (J Oral Maxillofac Surg 52:1269-72, 1994).

Frequency distributions were recorded for the condylar and disc positions at closed jaw.

Student's t-test with independent samples was used as test of significance to detect differences of condylar positions between the age cohorts (1930 vs. 1950) and the sexes. The significance levels were set at $5 \%$. First, the results from the measurement of the age cohorts were compared without differentiation of sexes, i.e., age cohort 1930-1932 versus age cohort 1950-1952. Subsequently, the age cohorts were compared by sex, i.e., men in cohort 1930-1932 versus men in cohort 1950-1952, and women in cohort 1930-1932 women men in cohort 1950-1952.

\footnotetext{
* Correspondence: jens.tuerp@unibas.ch

1Department of Reconstructive Dentistry and Temporomandibular Disorders,

University Center for Dental Medicine Basel, University of Basel, Basel,

Switzerland

Full list of author information is available at the end of the article
} 
(Continued from previous page)

Results: In both cohorts, condylar position was characterized by great variability. About $50 \%$ of the condyles were located centrically, while the other half was either in an anterior or in a posterior position. In both female cohorts, a posterior position predominated, whereas a centric position prevailed among men. Around $75 \%$ of the discs were positioned textbook-like, while the remaining forth was located anteriorly. Age had no statistically significant influence on condylar or on disc position. Conversely, comparison between the age groups revealed a statistically significant decrease of the depth of the glenoid fossa in both older cohorts. This age-dependent changes may be interpreted as flattening of the temporal joint surfaces.

Conclusions: We call for a re-interpretation of imaging findings because they may insinuate pathology which usually is not present. Instead, anterior or posterior positions of the mandibular condyle as well as an anterior location of the articular disc should be construed as a variation of normalcy. Likewise, flattening of articular surfaces of the TMJs may be considered as normal adaptive responses to increased loading, rather than pathological degenerative changes.

Trial registration: Not applicable.

Keywords: Image interpretation, Mandibular condyle, Medicalization, Medical overuse, Osteoarthritis, Osteoarthrosis, Overdiagnosis, Temporomandibular disorders, Temporomandibular joint disc, Terminology

\section{Background}

Many descriptive epidemiological studies from different countries have shown that temporomandibular disorders (TMDs) are mostly prevalent among women in the child-bearing age [1-4]. This is also reflected in the higher degree of TMD-related treatment need among females as compared to males $[5,6]$.

Conversely, recent findings from a large prospective cohort study (OPPERA) revealed that the incidence rate of clinically verified temporomandibular pain was only marginally greater in women than in men, while there was no difference in the annual rate of TMD pain symptom episodes among the two sexes [7]. In contrast to musculoskeletal complaints located in other parts of the body, e.g. osteoarthritis [8], the incidence and prevalence of TMD symptoms, notably pain located in the masticatory muscles and/or the temporomandibular joints (TMJs), decrease remarkably during menopause and in older age $[1,9,10]$.

In individuals with manifest or suspected TMDs, clinical decision-making as well as TMD-related prognostic statements of dentists are primarily based on somatic factors, such as the presence of temporomandibular pain, while psychosocial variables do not appear to play an important role, if any [6]. Traditionally, many dentists have focused on morphological variables to suggest etiological models and/or justify initiation of therapy, including (a) the position of the articular disc relative to the mandibular condyle [11, 12], (b) the location of the mandibular condyle relative to the temporal joint surfaces (glenoid fossa and articular eminence) [13, 14], and (c) the depth of the glenoid (mandibular) fossa, including flattening of the temporal surfaces $[15,16]$.

In the present investigation, these three anatomical variables were reanalyzed in two population-based birth cohorts to determine the prevalence of these variables and to (re)interpret the clinical significance of the findings. The cohorts were stratified by age and biological sex in order to investigate the possible influence of these two variables.

\section{Methods}

\section{Previous work}

At the beginning of the 1990s, a representative longitudinal population study of adult development based on two cohorts $(N=1001)$ born between 1930 and 1932 and between 1950 and 1952, respectively, had been initiated in two German urban regions, Heidelberg-MannheimLudwigshafen (Baden-Württemberg/ Rhineland-Palatinate) and Leipzig (Saxonia) [17]. In 2005 and 2006, the participants of our study had been recruited from the two Heidelberg cohorts by asking them to participate in a magnetic resonance imaging (MRI) examination of the TMJs. Seventy-two individuals consented, 33 of whom were from the birth cohort 1930-1932 and 39 from the cohort 19501952. Data of two subsamples - "cohort 1930-1932" [73-76 years of age], "cohort 1950-1952" [53-56 years of age]) of the Heidelberg cohort - was selected. The distribution of the 72 participants, stratified by cohort and sex, is summarized in Table 1 .

Subsequently, all subjects were examined according to the Research Diagnostic Criteria for Temporomandibular Disorders (RDC/TMD) [18]. Three participants reported pain in one TMJ. In five individuals, a reciprocal clicking was noticed during jaw opening, closing, and protrusion, but not upon protrusive opening. No subject had a limitation of mandibular movements.

In the Division of Radiology of the German Cancer Research Center at Heidelberg, contrast agent-enhanced 
Table 1 Distribution of the two birth cohorts

\begin{tabular}{llllll}
\hline & Number & $\mathrm{f}$ & $\mathrm{m}$ & Non-accessible, jaw closed & Non-accessible, jaw open \\
\hline Cohort 1930-1932 & 66 & 30 & 36 & 3 & 10 \\
Cohort 1950-1952 & 78 & 36 & 42 & 2 & 4 \\
$\Sigma$ TMJs & 144 & 66 & 78 & 5 & 14 \\
\hline
\end{tabular}

$\mathrm{N}$ : number of temporomandibular joints (TMJs), separated in TMJs from females ( $\mathrm{f}$ ) and males (m). At closed jaw, 139 TMJs were accessible, while 130 TMJs were accessible at open jaw. In the Cohort 1930-1932, one female participant could not be evaluated both at open and closed jaw

(Magnevist; Schering AG, Berlin, Germany) MRI scans of the TMJs in the sagittal and coronal views were made in open and closed jaw positions. For that purpose, a 1.5 Tesla tomography (Symphony; Siemens, Erlangen, Germany) with TMJ surface coils $(12 \mathrm{~cm}$ diameter; Siemens) was used. Imaging was carried out with a T1 2D fast low-angle shot (FLASH) sequence. For every individual, 10 scans were produced. The following settings were taken: slice thickness $3 \mathrm{~mm}$, distance factor $20 \%$, flip $30^{\circ}$, field of view $120 \mathrm{~mm} \times 120 \mathrm{~mm}$, time of repetition $208 \mathrm{~ms}$, time of echo $10.2 \mathrm{~ms}$, base resolution 256, phase resolution $80 \%$, band width $70 \mathrm{~Hz} / \mathrm{Px}$. The slices were oriented rectangular to the long axis of the condyle. The magnetization-prepared gradient echo technique was chosen to enhance the contrast of the various tissues by acquiring the spins in different relaxation times. This technique optimizes imaging of the cartilage and is both time- and cost-effective. For the depiction of the closed position, the subjects had been instructed to close their jaw habitually with slight tooth contacts. For the stabilization of the open jaw position, a mechanical mouth opener (Burnett BiDirectional TMJ Device, Medrad Inc. Pittsburgh, U.S.A.) was used to fix the open jaw position and, therefore, to reduce blurred images due to mandibular motion.

\section{Current study}

The total number of MRIs available for evaluation was 139 at closed and 130 at open jaw positions. Exclusion criteria had been low imaging quality and artifacts (Table 1). For each TMJ, one slice of the sagittal views namely the slice located in the middle of the long axis of the condyle - was selected from the open and closed positions, respectively, for the assessment of the mandibular condyle and the articular disc. For the purpose of this paper, the coronal views were not considered.

Evaluations of the MRIs and all measurements were carried out with the digitizing software DICOM (Digital Imaging and Communications in Medicine) Works (Version 1.3.5, National Electrical Manufactures Association, Virginia, USA).

\section{Position of the mandibular condyle at closed jaw}

The condylar position at closed jaw was calculated as percentage displacement of the condyle from absolute geometric centricity. Both the smallest anterior and posterior distances between mandibular condyle and glenoid fossa (i.e., the narrowest anterior and posterior interarticular widths) were determined $[19,20]$ (Fig. 1). Then, the individual condylar position (CP) was calculated according to the following formula $[19,20]$ :

$$
\mathrm{CP}=\frac{\text { posterior-anterior }}{\text { posterior }+ \text { anterior }} \times 100 \%
$$

The result was interpreted according to the recommendations by Ren et al. [21]:

- 0: absolute centric position of the condyle.

$-\quad-12 \%-+12 \%$ : centric position of the condyle

$-<-12 \%$ : posterior position of the condyle

$->+12 \%$ : anterior position of the condyle

\section{Position of the articular disc at closed jaw}

Determination of the articular disc position at closed jaw was carried out following the criteria proposed by Orsini et al. [22]. A textbook-like "normal" disc position (e.g.,[23]), with the posterior band located at the top of the condyle (12 o'clock position) (Fig. 2a), was distinguished from an anterior location, where in intercuspal position (formerly: maximum intercuspation) the posterior band of the disc was located anterior to the 12 o'clock position (Fig. 2b).

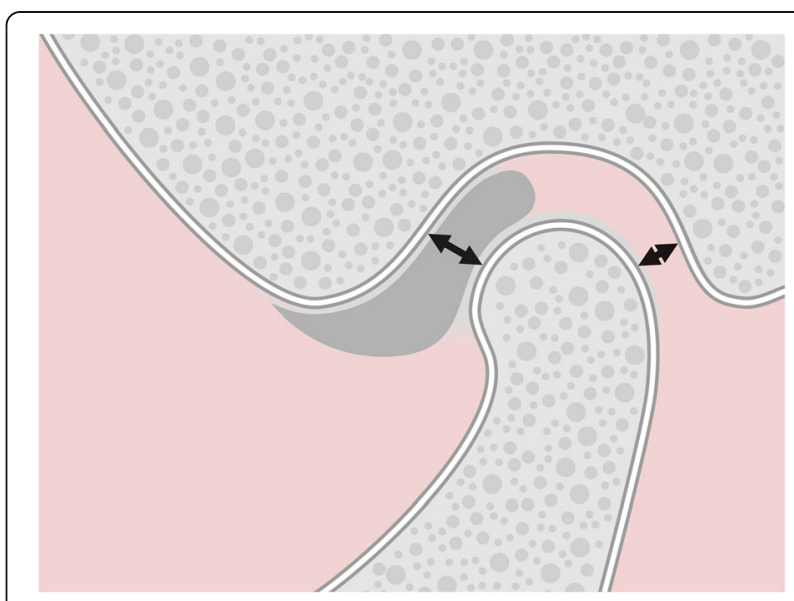

Fig. 1 Evaluation of condylar position at closed jaw: Determination of the smallest anterior and posterior joint spaces 


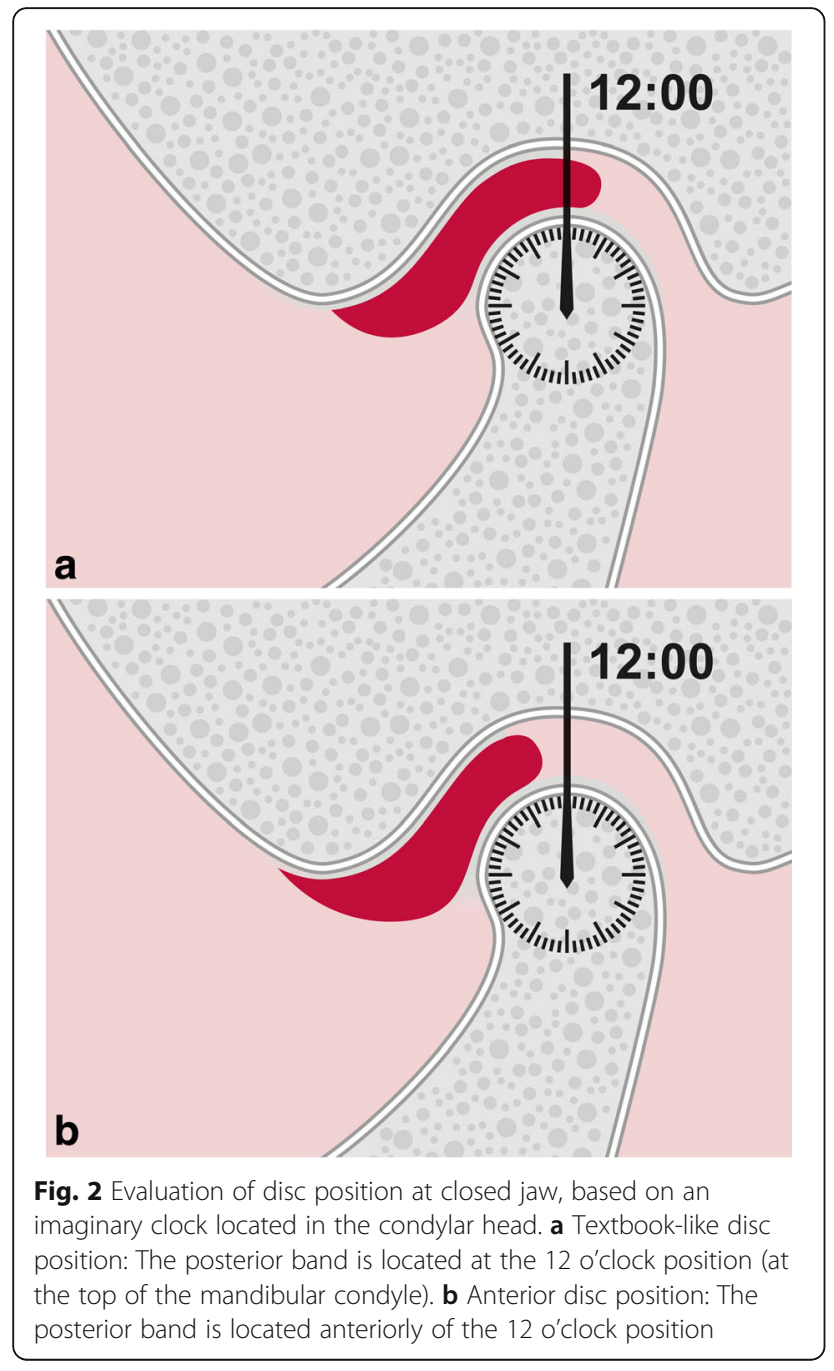

\section{Depth of the glenoid fossa at open jaw}

The depth of the glenoid fossa was assessed during open jaw position by using the method introduced by Muto et al. [24]: A tangent was drawn from the most caudal part of the articular eminence (E) to the apex of the postglenoid spine (S). The distance between $\mathrm{E}$ and $\mathrm{S}$, defined as "a", corresponded to the width of the glenoid fossa. Subsequently, a parallel line to SE touching the most superior aspect (F) of the fossa was drawn (P). Finally, a perpendicular line was drawn from $S E$ to $P$, which was equivalent to the depth (= height) of the fossa "b" (Fig. 3).

\section{Statistical evaluation}

The statistical analyses were carried out with SPSS version 21 (Statistical Package for the Social Sciences, Chicago, IL, USA). Frequency distributions were recorded for the condylar and disc positions at closed jaw. Student's $t$-test [25] with independent (unpaired) samples was used as test of significance to detect differences between the age cohorts (1930 vs. 1950) and the sexes. The significance levels were

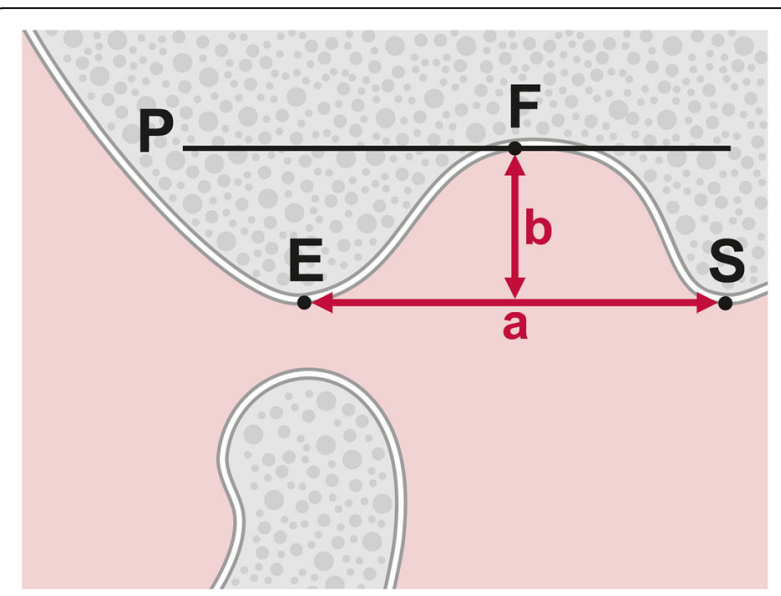

Fig. 3 Points and lines used for measuring glenoid fossa depth. C: highest point of the condyle, E: most caudal part of the articular eminence, F: most superior aspect of the glenoid fossa, S: apex of the postglenoid spine, $P$ : line parallel to the line SE touching $F$, a: distance from $E$ to $S$ = width of the fossa, $b$ : perpendicular line from SE to P1 = depth of the fossa

set at $5 \%$. First, the results from the measurement of the age cohorts were compared without differentiation of sexes, i.e., age cohort 1930-1932 versus age cohort 19501952. Subsequently, the age cohorts were compared by sex, i.e., men in cohort 1930-1932 versus men in cohort 1950-1952, and women in cohort 1930-1932 versus women in cohort 1950-1952.

\section{Interrater reliability}

To assess interrater reliability, the sagittal MRI views of the mandibular condyle and the articular disc of nine participants were evaluated at open and closed jaw positions independently by two authors (A.S. and M.S.) using the above-mentioned computerized digitizing software. The intra-class correlation coefficient [26] was used for the statistical computation. Based on the results of the reliability assessment (see Results: Interrater reliability), it was assumed that the measuring method was reliable. Therefore, the remaining MRIs were assessed by one rater only.

\section{Results}

\section{Interrater reliability}

Substantial interrater agreement could be reached (ICC: 0.7). Observational discrepancies were discussed until obtaining consensus.

\section{Position of the mandibular condyle at closed jaw}

In both cohorts, condylar position was characterized by great variability (Tables 2 and 3). Altogether, 68 of 139 condyles $(48.9 \%)$ were located centrically, whereas 71 (51.1\%) were in an eccentric position. An absolute centric position was a rare exception and was present in less 
Table 2 Condylar positions (jaw closed) among women and men, respectively, determined according to the formula $\frac{\text { posterior-anterior }}{\text { posterior+anterior }} \times 100 \%(n=139)$. There was no statistical significance in the relationship between the cohorts and the sexes, respectively

\begin{tabular}{|c|c|c|c|c|c|}
\hline & Anterior & Absolutely centric & Centric & Posterior & $\sum_{\text {TMJS }}$ \\
\hline Cohort 1930, women & $2(7 \%)$ & $2(7 \%)$ & $9(32 \%)$ & $15(54 \%)$ & 28 \\
\hline Cohort 1950, women & $3(8 \%)$ & $1(3 \%)$ & $13(36 \%)$ & $18(50 \%)$ & 35 \\
\hline Cohort 1930, men & $10(28 \%)$ & 0 & 17 (47\%) & $8(22 \%)$ & 35 \\
\hline Cohort 1950, men & $10(24 \%)$ & $2(5 \%)$ & $24(57 \%)$ & $5(12 \%)$ & 41 \\
\hline$\Sigma \mathrm{TMJS}$ & $25(18.0 \%)$ & $5(3.6 \%)$ & $63(45.3 \%)$ & $46(33.1 \%)$ & 139 \\
\hline
\end{tabular}

than $4 \%$ of individuals. In the female cohorts, a posterior position predominated $(52.4 \%)$, while a centric position prevailed among men (56.6\%). Nevertheless, neither age nor sex had a statistically significant influence on condylar position.

\section{Position of the articular disc at closed jaw}

In three-forth of the TMJs, the most frequent position of the articular disc corresponded to the one described in textbooks. With other words, one out of four discs was "anteriorly displaced" (Table 4). The frequency of anteriorly located disc was twice higher in females than in males $(22 / 63$ vs. $13 / 76=34.5 \%$ vs. $17.1 \%$; $p<0.05)$.

\section{Depth of the glenoid fossa at open jaw}

Comparison between the age groups revealed a statistically significant decrease $(p<0.05)$ of the depth of the glenoid fossa in both older cohorts: $6.9 \mathrm{~mm}$ (1950) vs. $6.1 \mathrm{~mm}$ (1930) among females, $7.8 \mathrm{~mm}$ (1950) vs. $6.3 \mathrm{~mm}$ (1930) among males (Table 5).

\section{Discussion}

\section{Methodology}

Our population-based retrospective cohort study was based on imaging data stored in an electronic database. The records were from individuals of a representative population sample. We therefore assume that the participants were representative of that population, hence minimizing selection bias [27]. The typical disadvantages of patient-based retrospective studies, such as recall bias

Table 3 Mean condylar position (jaw closed) among women and men, respectively, calculated according to the formula $\frac{\text { posterior-anterior }}{\text { posterior+anterior }} \times 100 \%(n=139)$. There was no statistical significance in the relationship between the cohorts and the sexes, respectively

\begin{tabular}{lrlll}
\hline & Mean & SD & Min & Max \\
\hline Cohort 1930, women & -20.7 & 23.5 & -100 & 14.8 \\
Cohort 1950, women & -11.4 & 19.1 & -45.5 & 40 \\
Cohort 1930, men & 1.8 & 19.5 & -40 & 40.3 \\
Cohort 1950, men & 5.1 & 13.6 & -42.3 & 31.8 \\
\hline
\end{tabular}

and information bias, did not affect the results because we made anatomical analyses on images, comparable to a histological examination. In our investigation, MRIs were used, which is the gold standard for imaging soft tissues [28]. In the temporomandibular joint area, MRIs are the images of choice to investigate disc position and optimize depiction of the condylar cartilage [29].

Conversely, for the investigation of hard tissues, such as condylar position and osseous changes, other imaging modalities, such as cone-beam computed tomography (CBCT), are more suitable $[30,31]$. Yet, in this population-based study, CT scans would not have been allowed by the ethical committee to be used. Without doubt, this is a certain methodological limitation, although, on the other hand, MRIs have been shown to produce highly acceptable osseous changes in the TMJ.

As the slices had been selected identically in each subject, the comparability of the results can be assumed to be valid. Without doubt, the orientation of the slices has an influence on the measurement. Since the orientation was standardized, however, this approach seems to be acceptable. In this context, the shape of the condyle has certainly an impact on the measurement of the condylar position. While the calculated depth of the glenoid fossa based on MRI data might differ from the real anatomical depth, this possible bias is true for all measurements in all subjects and might be acceptable for this reason.

Using the technique FLASH imaging for rapid MRI $[32,33]$ ensures that acquisition times are reduced to

Table 4 Distribution of disc positions (jaw closed) among women and men, respectively $(n=139)$. There was no statistical significance in the relationship between the cohorts and the sexes, respectively

\begin{tabular}{llll}
\hline & Anterior & Textbook-like & $\Sigma$ TMJs \\
\hline Cohort 1930, women & $7(25 \%)$ & $21(75 \%)$ & 28 \\
Cohort 1950, women & $15(42 \%)$ & $20(56 \%)$ & 35 \\
Cohort 1930, men & $9(25 \%)$ & $26(72 \%)$ & 35 \\
Cohort 1950, men & $4(10 \%)$ & $37(88 \%)$ & 41 \\
$\Sigma$ & $35(25.2 \%)$ & $104(74.8 \%)$ & 139 \\
\hline
\end{tabular}


Table 5 Depth of the glenoid fossa (distance "b") in mm (jaw open) among women and men, respectively $(n=130)$. Statistical significance was reached between the two female and the two male cohorts, respectively

\begin{tabular}{lcllrl}
\hline & Mean & SD & Min & Max & $p$ \\
\hline Cohort 1930, women & 6.1 & 1 & 3.6 & 7.7 & $<0.05$ \\
Cohort 1950, women & 6.9 & 1.3 & 4.5 & 9.4 & \\
Cohort 1930, men & 6.3 & 2.5 & 3.0 & 16.5 & $<0.05$ \\
Cohort 1950, men & 7.8 & 2 & 4.2 & 15.6 & \\
\hline
\end{tabular}

seconds while spatial resolution is retained. For the purpose of our study, three-dimensional (3D) imaging [34] could not be realized due to unavailability of the existing $3 \mathrm{D}$ magnetic resonance scanner and the higher costs due to the longer acquisition time.

\section{Position of the mandibular condyle at closed jaw}

We found a nearly 50\% chance (71:68) of a deviation from a centric condylar position. These results corroborate findings of two systematic reviews on the position of the mandibular condyles of symptom-free dentate adults during intercuspal position [35, 36]. Stamm et al. [35], who analyzed the results from 49 imaging investigations covering the period until 2001, reported a range of anterior (cranioventral), (con)centric and posterior condylar positions. No statistically significant predominance of any specific condylar position was observed when the results of the six methodically best study articles were considered [35].

In a sequel of the Stamm et al. review, Türp and Walter [36] evaluated the four study reports [37-41] and two overview articles $[42,43]$ that were published between 2002 and 2012. The results of the four clinical studies attested to the wide interindividual variation. Centric positions were found less frequently than eccentric locations of the condyles. This conclusion stands in contrast to data from a CBCT study in Iran where among individuals without TMD history a centric condylar position was the rule [44].

As in an early investigation report by Pullinger et al. [45], more posterior condylar positions were observed among females and more anterior positions among men. Pullinger et al. [45] raised the question whether this finding could "partially contribute to the greater frequency of TMJ clicking in females". Our study lends support to this hypothesis, because we identified twice as much anterior locations of the disc among women than among men.

Since in TMD patients an apparent association between condylar position and clinical findings worth to be treated is lacking [46], it appears that the often asked question of "the most physiological" or "the most optimum" condylar position in intercuspal position is more of academic interest than of clinical relevance. Instead, a relatively broad range of equally acceptable positions exists [36]. This assertion echoes the conclusion of Hugger et al. [37-41] who after analyzing 136 TMJs on MRIs stated: "Considering the great variability of the condylar position in patients with normal mandibular function and those with functional disorders of the stomatognathic system, the criterion "condyle-fossa relationship" seems more questionable than ever in the context of decision-making with regard to functional normality, adaptation or therapeutic requirements." Hence, by defining "normality" as a "range of results beyond which target disorders become highly probable" [47] we concur with the statement by Pullinger that "non-concentric condyle positions can be compatible with normal function" [48].

\section{Position of the articular disc at closed jaw}

Our observation that anterior disc locations are relatively frequent findings, is in concordance with imaging studies from the 1980s [49, 50] and 1990s [51]. More recent investigations have corroborated the assumption that so-called anterior disc displacements are common in normal populations. For example, in a community sample of 1643 individuals in Brazil, the prevalence of disc displacements as diagnosed clinically with the RDC/ TMD was around 8\% [52]. Not unexpectedly, higher values are found among patients. In a sample of 1603 adult TMD patients in Spain, the prevalence of the RDC/TMD diagnosis "disc displacement with reduction" was around 40\% in each TMJ [53]. Among 520 consecutive TMD patients in Italy, RDC/TMD diagnoses of disc displacement were found in $42 \%$ of cases [54]. The values from the two European studies are close to those found in our investigation. TMJ sounds are widespread even among children and adolescents, as was recently reported in a systematic review which considered 17,051 individuals: a prevalence of $10 \%$ (95\% confidence interval: 7.97-12.28) was calculated [55].

In the past, anterior disc displacements with reduction had been construed as the beginning of a cascade-like development leading to more severe TMJ pathology requiring therapy [56]. In the 1980s, Rasmussen [57] as well as Wilkes [58] proposed staging criteria for a progressive development of TMJ problems. While Rasmussen [57] differentiated six phases, Wilkes [58] distinguished five stages. Taking clinical, radiographic, and surgical findings into consideration, Wilkes postulated that a reciprocal TMJ clicking would eventually progress to pain of increasing frequency and intensity, leading to late stages of "chronicity" and "chronic restriction of [mandibular] motion" [58]. Yet, epidemiological population-based studies have challenged this view [59-61], which has also been corroborated by clinical findings among patient samples: 
In a recent cross-sectional multicenter study involving 614 cases with at least one TMD diagnosis, the association between TMJ intra-articular status (representing a transition from normal joint structure to TMJ disc displacement with or without reduction to degenerative joint disease) and patient-reported TMD impact (pain intensity, mandibular dysfunction, pain-related disability) was neither statistically significant nor clinically relevant [62]. In fact, the authors found no association between the intraarticular status of the TMJs and TMJ arthralgia or mandibular function [62]. Of course, these statements do not discard the possibility that a subset of individuals does indeed progress from clicking to osteoarthrosis; nonetheless, this is more an exception than the rule [48].

Accordingly, pain-free TMJ clicking (popping, snapping) during opening and/or closing [63], i.e. anterior disc displacement with reduction, may be interpreted as a "normal anatomical variant" presenting as subclinical symptom and/or sign that does not warrant further diagnosis or therapy [64] - as opposed to the alternative interpretation of an "abnormal joint pathology" [65]. The same applies to a pain-free disc displacement without reduction, which, in the absence of pain and/or mandibular dysfunction, should not be interpreted as a sign of pathology.

Although the line separating normal variation from pathological disorder is ill-defined, we agree with Ohrbach and Greene [64] that (a) pain associated with masticatory muscles or TMJs and/or (2) limitations of jaw movements (mostly restricted jaw opening), e.g. mandibular dysfunction, are those clinical symptoms and signs that require therapy, at least in most cases. Hence, painful TMJ clicking would warrant pain management, but irrespective of the presence of the clicking sound.

Imaging findings do not contribute to the clinical decision-making process because pain cannot be depicted on radiographs, whereas knowledge about the exact position of the articular disc appears to be unnecessary because there is no need for a therapeutic manipulation of the disc position. With other words: It is unnecessary to "confirm" a TMD-related diagnosis by sophisticated imaging. Instead, the principle of ALARA ("As Low As Reasonably Acceptable") or ALADA ("As Low As Diagnostically Acceptable") should be strictly observed [66].

\section{Depth of the glenoid fossa at open jaw}

The age-dependent changes observed in our study may be interpreted as flattening of the temporal joint surfaces, particularly of the posterior slope of the articular eminence. Radiographic observations, such as flattening of the mandibular condyles or the articular eminence, are common among asymptomatic individuals [67, 68] as well as among patients with TMJ pain [69]. These morphological alterations may begin at early age: In a Chinese investigation, 711 of 4883 TMD patients (14.6\%) aged between 11 and 30 years showed radiographic signs of TMJ osteoarthrosis [70]. The incidence of such osseous alterations continues with increasing age [71-73], probably as the consequence of long-term adverse loading of the intraarticular tissues [74], for example due to bruxism, while the role of loss of occlusal support on such morphological changes remains controversial [75].

Erosion with articular surface flattening is commonly interpreted as a sign of osteoarthrosis [76]. In the general population, the prevalence of TMJ osteoarthrosis lies between $2.4 \%$ [77] and 3.6\% [78], whereas among patient populations with TMDs the estimated prevalence is 5.5\% (based on seven studies representing 3,055 joints) [79]. In the joints of the human body, osseous changes, osteoarthritic pain, and impaired function generally increase with age $[8,80]$.

In contrast, the clinical symptoms of the typical TMD patient - a women between 18 und 50 year suffering from masticatory muscle pain - decrease remarkably during menopause and in older age groups [1]. Schmitter et al., for instance, found that among thirty 73 to 75 years old individuals drawn from a representative sample signs of TMJ osteoarthrosis were detected on gadoliniumenhanced MR images in 21 subjects (70\%); yet, only one person (3.3\%) reported TMJ arthralgia [9]. De Leeuw et al. [81] reported that 30 years after initial diagnosis of osteoarthrosis and internal derangement clinical signs were scarce and did hardly differ from those of asymptomatic controls, despite the fact that radiographic signs, such as flattening, were significantly more prevalent in former patients than in controls.

These findings support a statement of De Boever and Carlsson made more than two decades ago [82]. They noted that "many patients are unaware of the deviation in form and the case history is often negative for pain or acute dysfunction", because "it may well be a remodeling due to changed function", leading to pain-free adaptive changes of the osseous structures of the TMJ [83]. Therefore, TMJs with signs of osteoarthrosis are not necessarily associated with more symptoms of TMDs than TMJs without osteoarthrosis $[84,85]$. On the other hand, clinical signs and symptoms of TMJ osteoarthritis are poorly correlated with osseous changes depicted with computed tomography [86] or CBCT [30]. Indeed, for a long time it has been known that on the basis of radiographic findings it is difficult to differentiate between osteoarthrosis and adaptive remodeling [87]. Thus, an irregular morphology of the TMJ, such loss of the rounded contour of the surface of the mandibular condyle and/or the posterior slope of the articular eminence, has been considered an indeterminate finding for DJD, 
Table 6 Suggested new description of three traditional imaging and clinical findings

\begin{tabular}{ll}
\hline Traditional description & Suggested new description \\
\hline $\begin{array}{l}\text { Condylar displacement } \\
\text { (eccentric condylar position) }\end{array}$ & (Anterior, posterior) condylar position \\
Anterior disc displacement & Anterior disc position \\
Osteoarthrosis & $\begin{array}{l}\text { Adaptive remodeling (due to } \\
\text { increased mechanical loading) }\end{array}$ \\
\hline
\end{tabular}

which may represent a precursor to osteoarthrosis, but also variation of normalcy, a sign of aging, and/or adaptive remodeling $[63,88]$. Indeed, since the classical papers by Sandstedt more than 120 years ago [89-91], it is part of the general knowledge of the dental community that continuous compression may lead to bone resorption, while traction (pull) may cause deposition of new bone (bone apposition). Therefore, we argue that repetitive mechanical load by compressive forces that exceeds the adaptive capacity of the TMJ may result in resorption of bone and flattening of formerly roundish joint surfaces of the mandibular condyle and the articular eminence [92, 93]. From a biological standpoint of plausibility, this would allow for a greater distribution of mechanical forces acting on the joint, for example during bruxing episodes, and could be interpreted as a bony adaptation [94].

\section{Conclusions}

Based on the results of our investigation and following the arguments put forth in the discussion, we call for a re-interpretation of the significance and labeling of imaging findings and derived diagnoses because they may insinuate pathology which usually does not exist. Therefore, as far as the mandibular condyles are concerned, expressions such as "condylar displacement" or "eccentric position" for describing of a non-centric condylar position should be avoided. Besides, it may evoke negative cognitions among patients. This interjection also applies to the prevalent diagnoses "anterior disc displacement" and "degenerative joint disease"/ "TMJ osteoarthrosis". In most cases, these conditions are chance findings in the course of a clinical or imaging examination, with no disadvantageous outcomes for the individual. Two decades ago, relabeling of the expression "disc displacement" (in favor of "disc position") had been already suggested [95]. We would like to extend our proposal by considering condylar position and TMJ morphology as well (Table 6). By doing so, we intend to protect non-patients against medicalization, overdiagnosis, and unnecessary therapy.

\section{Abbreviations}

cm: Centimeter; CP: Condylar position; DC/TMD: Diagnostic Criteria for Temporomandibular Disorders; DJD: Degenerative joint disease; Hz/Px: Herz/ Pixel [Bandwidth]; mm: Millimeter; MRI: Magnetic resonance imaging; ms: Millisecond; OPPERA: Orofacial Pain: Prospective Evaluation and Risk Assessment; RDC/TMD: Research Diagnostic Criteria for Temporomandibular Disorders; TMD: Temporomandibular disorders; TMJ: Temporomandibular joint

\section{Acknowledgements}

We would like to thank Mrs. Tine Ade, graphic designer, for preparing the figures. We also appreciate the thorough and very helpful suggestions of the reviewers. Their insightful and constructive comments have helped us improve and strengthen our manuscript.

Finally, we would like to express our gratitude to the Ministry of Science, Research, and Arts of the State of Baden-Württemberg, Germany; to the Federal Ministry for Family Affairs, Senior Citizens, Women, and Youth of the Federal Republic of Germany; and to the Dietmar Hopp Stiftung (Foundation), Germany.

\section{Funding}

Not applicable.

\section{Availability of data and materials}

We state that the clinical data and personal details associated with the MRIs will not be made available in order to protect the participants' identity.

\section{Authors' contributions}

JCT reinterpreted the data, drafted and wrote the manuscript. AS analyzed the MRIs, carried out the statistical analyses, and contributed to the manuscript. JS designed the study and recruited the patients. ME examined the subjects and analyzed the MRIs. MS designed the study, interpreted the data, and contributed to the manuscript. All authors read and approved the final manuscript.

\section{Competing interests}

The authors declare that they have no competing interests.

\section{Ethics approval and consent to participate}

Ethics approval was granted by the Ethics Committee of the Medical Faculty of the University of Heidelberg (approval number 181/2005). Written informed consent to participate in the investigation was obtained from each study participant.

\section{Author details}

${ }^{1}$ Department of Reconstructive Dentistry and Temporomandibular Disorders, University Center for Dental Medicine Basel, University of Basel, Basel, Switzerland. ${ }^{2}$ Department of Prosthodontics, University of Heidelberg, Heidelberg, Germany. ${ }^{3}$ Section of Geriatric Psychiatry, University of Heidelberg, Heidelberg, Germany. ${ }^{4}$ Department of Radiology, University of Manitoba, Faculty of Medicine, Winnepeg, Canada. ${ }^{5}$ Department of Prosthodontics, Dental School of the University of Würzburg, Würzburg, Germany.

Received: 24 June 2016 Accepted: 9 November 2016

Published online: 17 November 2016

\section{References}

1. Howard JA. Temporomandibular joint disorders, facial pain, and dental problems in performing artists. In: Sataloff RT, Brandfonbrener AG Lederman RJ, editors. Textbook of performing arts medicine. New York: Raven; 1991. p. 111-69.

2. Al-Jundi MA, John MT, Setz JM, Szentpétery A, Kuss O. Meta-analysis of treatment need for temporomandibular disorders in adult nonpatients. J Orofacial Pain. 2008;22:97-107.

3. Visscher CM, Ligthart L, Schuller AA, Lobbezoo F, de Jongh A, van Houtem CM, Boomsma DI. Comorbid disorders and sociodemographic variables in temporomandibular pain in the general Dutch population. J Oral Facial Pain Headache. 2015:29:51-9.

4. Kim TY, Shin JS, Lee J, Lee YJ, Kim MR, Ahn YJ, Park KB, Hwang DS, Ha IH. Gender difference in associations between chronic temporomandibular disorders and general quality of life in Koreans: a cross-sectional study. PLoS One. 2015;10:e0145002.

5. Kuttila M, Niemi PM, Kuttila S, Alanen P, Le Bell Y. TMD treatment need in relation to age, gender, stress, and diagnostic subgroup. J Orofac Pain. 1998 12:67-74. 
6. Yekkalam N, Wanman A. Factors associated with clinical decision-making in relation to treatment need for temporomandibular disorders. Acta Odontol Scand. 2016;74:134-41.

7. Slade GD, Sanders AE, Bair E, Brownstein N, Dampier D, Knott C, Fillingim R, Maixner WO, Smith S, Greenspan J, et al. Preclinical episodes of orofacial pain symptoms and their association with health care behaviors in the OPPERA prospective cohort study. Pain. 2013;154:750-60.

8. Neogi T, Zhang Y. Epidemiology of osteoarthritis. Rheum Dis Clin North Am. 2013;39:1-19.

9. Schmitter M, Essig M, Seneadza V, Balke Z, Schröder J, Rammelsberg P. Prevalence of clinical and radiographic signs of osteoarthrosis of the temporomandibular joint in an older persons community. Dentomaxillofac Radiol. 2010:39:231-4.

10. Levitt SR, MCKinney MW. Validating the TMJ scale in a national sample of 10,000 patients: demographic and epidemiologic characteristics. J Orofac Pain. 1994;8:25-35.

11. McCarty WL, Farrar WB. Surgery for internal derangements of the temporomandibular joint. J Prosthet Dent. 1979;42:191-6.

12. Liu MQ, Chen HM, Yap AU, Fu KY. Condylar remodeling accompanying splint therapy: a cone-beam computerized tomography study of patients with temporomandibular joint disk displacement. Oral Surg Oral Med Oral Pathol Oral Radiol. 2012;114:259-65.

13. Weinberg LA. Practical evaluation of the lateral temporomandibular joint radiograph. J Prosthet Dent. 1984;51:676-85

14. Endo M, Terajima M, Goto TK, Tokumori K, Takahashi I. Three-dimensional analysis of the temporomandibular joint and fossa-condyle relationship. Orthodontics (Chic). 2011;12:210-21.

15. Tanaka T, Morimoto Y, Tanaka Y, Kobayashi S, Okumura Y, Kito S, Okabe S, Ohba T. Radiographic examination of the mandibular (glenoid) fossa in ancient and modern man. Oral Dis. 2004:10:369-77.

16. Paknahad M, Shahidi S, Akhlaghian M, Abolvardi M. Is mandibular fossa morphology and articular eminence inclination associated with temporomandibular dysfunction? J Dent (Shiraz). 2016;17:134-41.

17. Martin P, Grünendahl M, Schmitt M. Persönlichkeit, kognitive Leistungsfähigkeit und Gesundheit in Ost und West: Ergebnisse der Interdisziplinären Längsschnittstudie des Erwachsenenalters (ILSE). [Personality, cognitive ability and health in East and West Germany: results of an interdisciplinary longitudinal study of aging]. Z Gerontol Geriatr. 2000;33:111-23.

18. Dworkin SF, LeResche $\mathrm{L}$. Research diagnostic criteria for temporomandibular disorders: review, criteria, examinations and specifications, critique. J Craniomandib Disord Facial Oral Pain. 1992;6:301-55.

19. Pullinger $A$, Hollender $L$. Assessment of mandibular condyle position: a comparison of transcranial radiographs and linear tomograms. Oral Surg Oral Med Oral Pathol. 1985;60:329-34.

20. Pullinger A, Hollender L. Variation in condyle-fossa relationships according to different methods of evaluation in tomograms. Oral Surg Oral Med Ora Pathol. 1986;62:719-27.

21. Ren YF, Isberg A, Westesson PL. Condyle position in the temporomandibular joint. Comparison between asymptomatic volunteers with normal disk position and patients with disk displacement. Oral Surg Oral Med Oral Pathol Oral Radiol Endod. 1995;80:101-7.

22. Orsini MG, Kuboki T, Terada S, Matsuka Y, Yamashita A, Clark GT. Diagnostic value of 4 criteria to interpret temporomandibular joint normal disk position on magnetic resonance images. Oral Surg Oral Med Oral Pathol Oral Radiol Endod. 1998:86:489-97.

23. Bermejo-Fenoll A. Anatomy of the temporomandibular joint and masticatory muscles. In: Manfredini D, editor. Current concepts on temporomandibular disorders. London: Quintessence; 2010. p. 3-24. here: 5-7.

24. Muto T, Kohara M, Kanazawa M, Kawakami J. The position of the mandibular condyle at maximal mouth opening in normal subjects. J Oral Maxillofac Surg. 1994;52:1269-72.

25. Student. The probable error of a mean. Biometrika. 1908:6:1-25.

26. Koch GG. Intraclass correlation coefficient. In: Kotz S, Johnson NL, editors. Encyclopedia of Statistical Sciences. New York: Wiley; 1982. p. 213-7.

27. Sedgwick P. Retrospective cohort studies: advantages and disadvantages. BMJ. 2014;348:91072

28. Torres MG, Crusoe-Rebello IM, Rosario M, Albuquerque MC, Campos PS. Morphometric features of the mandibular condyle and association with disk abnormalities. Oral Surg Oral Med Oral Pathol Oral Radiol. 2016;121:566-72.

29. Abe S, Kawano F, Kohge K, Kawaoka T, Ueda K, Hattori-Hara E, Mori H, Kuroda S, Tanaka E. Stress analysis in human temporomandibular joint affected by anterior disc displacement during prolonged clenching. J Oral Rehabil. 2013:40:239-46.

30. Cömert Kiliç S, Kiliç N, Sümbüllü MA. Temporomandibular joint osteoarthritis: cone beam computed tomography findings, clinical features, and correlations. Int J Oral Maxillofac Surg. 2015;44:1268-74.

31. Larheim TA, Abrahamsson AK, Kristensen M, Arvidsson LZ. Temporomandibular joint diagnostics using CBCT. Dentomaxillofac Radiol. 2015;44:20140235.

32. Haase A, Frahm J, Matthaei D, Hänicke W, Merboldt KD. FLASH imaging: rapid NMR imaging using low flip-angle pulses. J Magn Reson. 1986;67:258-66.

33. Haase A. FLASH MR, imaging: a success story since 25 years. J Magn Reson. $2011 ; 213: 542-3$

34. Frahm J, Haase A, Matthaei D. Rapid three-dimensional MR imaging using the FLASH technique. J Comput Assist Tomogr. 1986;10:363-8.

35. Stamm T, Hohoff A, Van Meegen A, Meyer U. On the three-dimensional physiological position of the temporomandibular joint. J Orofac Orthop. 2004;65:280-9.

36. Türp JC, Walther M. The anteroposterior condylar position in maximum intercuspation in the dentate adult. J Craniomand Funct. 2014;6:9-20.

37. Incesu L, Taşkaya-Yilmaz N, Öğütcen-Toller M, Uzun E. Relationship of condylar position to disc position and morphology. Eur J Radiol. 2004;51:269-73.

38. Menezes AV, de Almeida SM, Boscolo FN, Haiter-Neto F, Ambrosano GM, Manzi FR. Comparison of transcranial radiograph and magnetic resonance imaging in the evaluation of mandibular condyle position. Dentomaxillofac Radiol. 2008;37:293-9.

39. Mupparapu M, Chow I, Uppal A. Hard tissue structural changes in TMJ morphology prior to orthodontic therapy: a complex motion tomographic study. Quintessence Int. 2011;42:427-34.

40. Almăşan $O C$, Hedeşiu M, Baciuț $G$, Leucuța DC, Băciuț M. Disk and joint morphology variations on coronal and sagittal MRI in temporomandibular joint disorders. Clin Oral Investig. 2012;17:1243-50.

41. Hugger A, Sons T, Kordaß B, Assheuer J, Stüttgen U. Analyse der Kondylenposition im sagittalen Kernspintomogramm [Analysis of the condylar position in the sagittal magnetic resonance tomogram]. Dtsch Zahnärztl Z. 1999;54:380-3.

42. Gonzalez B. The not-so-controversial issue of condylar position. Int J Orthod Milwaukee. 2007;18:17-26.

43. Rinchuse DJ, Kandasamy S. Centric relation: A historical and contemporary orthodontic perspective. J Am Dent Assoc. 2006;137:494-501.

44. Dalili Z, Khaki N, Kia SJ, Salamat F. Assessing joint space and condylar position in the people with normal function of temporomandibular joint with cone-beam computed tomography. Dent Res J (Isfahan). 2012;9:607-12

45. Pullinger AG, Hollender $L$, Solberg WK, Petersson A. A tomographic study of mandibular condyle position in an asymptomatic population. J Prosthet Dent. 1985:53:706-13.

46. Paknahad M, Shahidi S, Iranpour S, Mirhadi S. Cone-Beam computed tomographic assessment of mandibular condylar position in patients with temporomandibular joint dysfunction and in healthy subjects. Int J Dent. 2015:2015:301796.

47. Straus SE, Richardson WS, Glasziou P, Haynes RB. Evidence-Based Medicine How to Practice and Teach EBM. 3rd ed. Edinburgh: Churchill Livingstone; 2005. here: 69

48. Pullinger A. Establishing better biological models to understand occlusion. I: TM joint anatomic relationships. J Oral Rehabil. 2013;40:296-318.

49. Wiesel SW, Tsourmas N, Feffer HL, Citrin CM, Patronas N. A study of computer-assisted tomography I The incidence of positive CAT scans in an asymptomatic group of patients. Spine. 1984:9:549-51.

50. Westesson P-L, Eriksson L, Kurita K. Reliability of a negative clinical temporomandibular joint examination: prevalence of disk displacement in asymptomatic temporomandibular joints. Oral Surg Oral Med Oral Pathol. 1989;68:551-4.

51. Katzberg RW, Westesson PL, Tallents RH, Drake CM. Anatomic disorders of the temporomandibular joint disc in asymptomatic subjects. J Oral Maxillofac Surg. 1996:54:147-53.

52. Progiante PS, Pattussi MP, Lawrence HP, Goya S, Grossi PK, Grossi ML. Prevalence of temporomandibular disorders in an adult Brazilian community population using the Research Diagnostic Criteria (Axes I and II) for Temporomandibular Disorders (The Maringá Study). Int J Prosthodont. 2015;28:600-9.

53. Blanco-Hungría A, Blanco-Aguilera A, Blanco-Aguilera E, Serrano-Del-Rosal R, Biedma-Velázquez L, Rodríguez-Torronteras A, Segura-Saint-Gerons R. 
Prevalence of the different Axis I clinical subtypes in a sample of patients with orofacial pain and temporomandibular disorders in the Andalusian Healthcare Service. Med Oral Patol Oral Cir Bucal. 2016;21:e169-77.

54. Manfredini D, Arveda N, Guarda-Nardini L, Segu M, Collesano V. Distribution of diagnoses in a population of patients with temporomandibular disorders. Oral Surg Oral Med Oral Pathol Oral Radiol. 2012;114:e35-41.

55. da Silva CG, Pachêco-Pereira C, Porporatti AL, Savi MG, Peres MA, Flores-Mir C, Canto GL. Prevalence of clinical signs of intra-articular temporomandibular disorders in children and adolescents: A systematic review and meta-analysis. J Am Dent Assoc. 2016;147:10-8. e8.

56. Rammelsberg P, Pospiech P, Heumann C, Toutenburg H. Ätiologische Faktoren für Diskusverlagerungen im Kiefergelenk [Etiologic factors for disc displacement in the temporomandibular joint.]. Dtsch Zahnärztl Z. 1996;51:211-8.

57. Rasmussen OC. Description of population and progress of symptoms in a longitudinal study of temporomandibular arthropathy. Scand J Dent Res. 1981;89:196-203.

58. Wilkes $\mathrm{CH}$. Internal derangements of the temporomandibular joint. Pathological variations. Arch Otolaryngol Head Neck Surg. 1989;115:469-77.

59. Könönen $M$, Waltimo $A$, Nyström $M$. Does clicking in adolescence lead to painful temporomandibular joint locking? Lancet. 1996;347:1080-1.

60. Torii K. Longitudinal course of temporomandibular joint sounds in Japanese children and adolescents. Head Face Med. 2011;7:17.

61. Egermark I, Carlsson GE, Magnusson T. A 20-year longitudinal study of subjective symptoms of temporomandibular disorders from childhood to adulthood. Acta Odontol Scand. 2001;59:40-8.

62. Chantaracherd P, John MT, Hodges JS, Schiffman EL. Temporomandibular joint disorders' impact on pain, function, and disability. J Dent Res. 2015;94: 795-86.

63. de Leeuw R, Klasser GD. Orofacial pain: guidelines for assessment, diagnosis, and management. 5th ed. Chicago: Quintessence; 2013. here: 139-43.

64. Ohrbach R, Greene C. Temporomandibular joint diagnosis: striking a balance between the sufficiency of clinical assessment and the need for imaging. Oral Surg Oral Med Oral Pathol Oral Radiol. 2013;116:124-5.

65. Rohlin $\mathrm{M}$, Westesson PL, Eriksson L. The correlation of temporomandibular joint sounds with joint morphology in fifty-five autopsy specimens. J Oral Maxillofac Surg. 1985:43:194-200.

66. Berkhout WE. Het ALARA-principe. Achtergronden en toepassing in de praktijk. The ALARA-principle. Backgrounds and enforcement in dental practices.]. Ned Tijdschr Tandheelkd. 2015;122:263-70.

67. Muir CB, Goss AN. The radiologic morphology of asymptomatic temporomandibular joints. Oral Surg Oral Med Oral Pathol. 1990;70:349-54.

68. Brooks SL, Westesson PL, Eriksson L, Hansson LG, Barsotti JB. Prevalence of osseous changes in the temporomandibular joint of asymptomatic persons without internal derangement. Oral Surg Oral Med Oral Pathol. 1992;73:118-22.

69. Muir CB, Goss AN. The radiologic morphology of painful temporomandibular joints. Oral Surg Oral Med Oral Pathol. 1990;70:355-9.

70. Zhao YP, Zhang ZY, Wu YT, Zhang WL, Ma XC. Investigation of the clinical and radiographic features of osteoarthrosis of the temporomandibular joints in adolescents and young adults. Oral Surg Oral Med Oral Pathol Oral Radiol Endod. 2011;111:e27-34.

71. Ishibashi H, Takenoshita Y, Ishibashi K, Oka M. Age-related changes in the human mandibular condyle: a morphologic, radiologic, and histologic study. J Oral Maxillofac Surg. 1995:53:1016-23. discussion 23-4.

72. Widmalm SE, Westesson PL, Kim IK, Pereira Jr FJ, Lundh H, Tasaki MM. Temporomandibular joint pathosis related to sex, age, and dentition in autopsy material. Oral Surg Oral Med Oral Pathol. 1994;78:416-25.

73. Pereira Jr FJ, Lundh H, Westesson PL. Morphologic changes in the temporomandibular joint in different age groups. An autopsy investigation. Oral Surg Oral Med Oral Pathol. 1994;78:279-87.

74. Hansson TL. Pathological aspects of arthritides and derangements. In: Sarnat BG, Laskin DM, editors. The temporomandibular joint: a biological basis for clinical practice. 4th ed. Philadelphia: Saunders; 1992. p. 165-82. here: 171.

75. Magnusson C, Nilsson M, Magnusson T. Degenerative changes of the temporomandibular joint. Relationship to ethnicity, sex and occlusal supporting zones based on a skull material. Acta Odontol Scand. 2012;70:207-12.

76. de Leeuw R, Boering G, Stegenga B, de Bont LG. Radiographic signs of temporomandibular joint osteoarthrosis and internal derangement 30 years after nonsurgical treatment. Oral Surg Oral Med Oral Pathol Oral Radiol Endod. 1995;79:382-92.

77. Rantala MA, Ahlberg J, Suvinen TI, Savolainen A, Könönen M. Symptoms, signs, and clinical diagnoses according to the research diagnostic criteria for temporomandibular disorders among Finnish multiprofessional media personnel. J Orofac Pain. 2003;17:311-6.

78. Abrahamsson C, Ekberg E, Henrikson T, Nilner M, Sunzel B, Bondemark L. TMD in consecutive patients referred for orthognathic surgery. Angle Orthod. 2009;79:621-7.

79. Manfredini D, Guarda-Nardini L, Winocur E, Piccotti F, Ahlberg J, Lobbezoo F. Research diagnostic criteria for temporomandibular disorders: a systematic review of axis I epidemiologic findings. Oral Surg Oral Med Oral Pathol Oral Radiol Endod. 2011;112:453-62.

80. Johnson VL, Hunter DJ. The epidemiology of osteoarthritis. Best Pract Res Clin Rheumatol. 2014:28:5-15.

81. de Leeuw R, Boering G, van der Kuij B, Stegenga B. Hard and soft tissue imaging of the temporomandibular joint 30 years after diagnosis of osteoarthrosis and internal derangement. J Oral Maxillofac Surg. 1996;54: 1270-80.

82. De Boever JA, Carlsson GE. Etiology and differential diagnosis. In: Zarb GA Carlsson GE, Sessle BE, Mohl ND, editors. Temporomandibular Joint and Masticatory Muscle Disorders. Copenhagen: Munksgaard - Mosby; 1994. p. 171-87. here: 183-184.

83. Okeson JP. Bell's oral and facial pain. 7th ed. Chicago: Quintessence; 2014. here: 348 .

84. Wiberg B, Wänman A. Signs of osteoarthrosis of the temporomandibular joints in young patients: a clinical and radiographic study. Oral Surg Oral Med Oral Pathol Oral Radiol Endod. 1998:86:158-64.

85. Lee JY, Kim DJ, Lee SG, Chung JW. A longitudinal study on the osteoarthritic change of the temporomandibular joint based on 1-year follow-up computed tomography. J Craniomaxillofac Surg. 2012;40:e223-8.

86. Kim K, Wojczynska A, Lee JY. The incidence of osteoarthritic change on computed tomography of Korean temporomandibular disorder patients diagnosed by RDC/TMD; a retrospective study. Acta Odontol Scand. 2016;74: 337-42.

87. Haskin CL, Milam SB, Cameron IL. Pathogenesis of degenerative joint disease in the human temporomandibular joint. Crit Rev Oral Biol Med. 1995;6:248-77.

88. Milano V, Desiate A, Bellino R, Garofalo T. Magnetic resonance imaging of temporomandibular disorders: classification, prevalence and interpretation of disc displacement and deformation. Dentomaxillofac Radiol. 2000;29:352-61.

89. Sandstedt C. Einige Beiträge zur Theorie der Zahnregulierung [Some contributions to the theory of the regualtion of teeth]. Nordisk Tandlak Tidskr. 1904;5:236-56.

90. Sandstedt C. Einige Beiträge zur Theorie der Zahnregulierung [Some contributions to the theory of the regualtion of teeth]. Nordisk Tandlak Tidskr. 1905:6:1-25, 141-68.

91. Bister D, Meikle MC. Re-examination of 'Einige Beiträge zur Theorie der Zahnregulierung' (Some contributions to the theory of the regulation of teeth) published in 1904-1905 by Carl Sandstedt. Eur J Orthod. 2013;35: $160-8$.

92. Mongini F. Dental abrasion as a factor in remodeling of the mandibular condyle. Acta Anat. 1975;92:292-300.

93. Yamada K, Tsuruta A, Hanada K, Hayashi T. Morphology of the articular eminence in temporomandibular joints and condylar bone change. J Oral Rehabil. 2004:31:438-44.

94. Nishio C, Tanimoto K, Hirose M, Horiuchi S, Kuroda S, Tanne K, Tanaka E. Stress analysis in the mandibular condyle during prolonged clenching: a theoretical approach with the finite element method. Proc Inst Mech Eng $\mathrm{H}$. 2009;223:739-48.

95. Türp JC. Diskusverlagerungen neu überdacht [Disc displacements revisited]. Dtsch Zahnärztl Z. 1998:53:369-73. 